\title{
Competências e formação em psicologia: diretrizes para o Sistema Único de Saúde
}

\author{
Skills and training in psychology: \\ guidelines for the Unified Health System
}

\section{Ítalo Pereira Coêlho' 1 () Moema Alves Macêdo ${ }^{2}$ ()}

${ }^{1}$ Autor para correspondência. Centro Universitário Dr. Leão Sampaio (Juazeiro do Norte). Ceará, Brasil. italocoelho8@hotmail.com ${ }^{2}$ Centro Universitário Dr. Leão Sampaio (Juazeiro do Norte). Ceará, Brasil. moema@leaosampaio.edu.br

\begin{abstract}
RESUMO | Este trabalho tem como objetivo a compreensão das possíveis relações existentes entre as competências apontadas pelas Diretrizes Curriculares Nacionais de Psicologia com as Referências Técnicas publicadas pelo Centro de Referência Técnica em Psicologia e Políticas Públicas (CREPOP). Trata-se de uma pesquisa documental, tendo como metodologia a análise do discurso. Após a leitura flutuante das referências técnicas produzidas pelo CREPOP entre janeiro de 2007 a setembro de 2019, foram selecionados quatro documentos para a pesquisa. Estes foram lidos na íntegra, realizando-se um fichamento e a construção de mapas dialógicos dos capítulos relacionados às práticas profissionais. Observou-se a existência de uma maior relação com as competências de atenção à saúde e educação permanente. As demais competências liderança, tomada de decisão e administração e gerenciamento sendo ampliadas para formas de atuação compartilhadas. Além disso, foi possível observar discursos que faziam menção a outras competências que acabavam ampliando a atuação da psicologia, mas que não são apontadas pelas diretrizes curriculares, como o trabalho com clínica ampliada, diálogo, trabalho colaborativo e ética dialógica.
\end{abstract}

PALAVRAS-CHAVE: Competência. Formação profissional. Psicologia. Sistema Único de Saúde.

\begin{abstract}
This work aims to understand the possible relationships between the competences pointed out by the National Curriculum Guidelines for Psychology with the Technical References published by the Technical Reference Center in Psychology and Public Policies (CREPOP). It is a documentary research, using the discourse analysis methodology. After the floating reading of the technical references produced by CREPOP between January 2007 and September 2019, four documents were selected for the research. These were read in their entirety, a file was created and the construction of dialogical maps of the chapters related to professional practices. It was observed that there is a greater relationship with the competence of health care and permanent education. The other competencies of leadership, decision making and administration and management are being extended to shared forms of action. In addition, it was possible to observe speeches that mentioned other competencies that ended up expanding the performance of psychology, but that are not pointed out by the curriculum guidelines, such as working with an expanded clinic, dialogue, collaborative work and dialogic ethics.
\end{abstract}

KEYWORDS: Competence. Professional education. Psychology. Unified Health System. 


\section{Introdução}

A criação do Sistema Único de Saúde (SUS) exerceu grande influência na compreensão e identificação das necessidades de possíveis mudanças nos currículos dos cursos de saúde em todo país. Estas mudanças tinham como objetivo o preparo de profissionais na área da saúde capazes de desenvolver uma visão ampla em relação ao trabalho em equipe, uma ampliação na concepção de saúde e um maior compromisso na prestação do cuidado integral (Santos, Batista \& Batista, 2014).

A necessidade dessas mudanças acontece sobretudo para atingir o horizonte dos princípios e diretrizes do Sistema, em especial: universalidade, equidade, integralidade. Esse horizonte demarca a necessidade de um posicionamento político-pedagógico nas formações voltadas para a construção social de um projeto democrático compartilhado nos processos de cuidado em saúde.

Com isso, o processo de formação em saúde gera debate nas profissões da área, fazendo com que o estudante adquira uma concepção de saúde que vai além das questões voltadas para a saúde-doença nas esferas anatômicas e fisiológicas, englobando também as esferas subjetivas e sociais em uma perspectiva saúde-doença-cuidado. Essa formação ainda deve ser capaz de aproximar os estudantes das comunidades e serviços de saúde, repensando sua prática formativa, tendo em vista que estes estariam diretamente em contato com necessidades da população/comunidade a qual estão inseridos (Pitombeira, Xavier, Barroso \& Oliveira, 2016).

Visando a efetivação do sistema de saúde no país, o Ministério da Saúde, junto ao Ministério da Educação, tendo como principal objetivo a seguridade de uma formação curricular para os cursos de saúde alinhados com aquilo que é preconizado pelo SUS, promulgam as Diretrizes Curriculares Nacionais (DCN's) para 14 cursos da área da saúde em todo o Brasil, visando a reorientação na forma de se pensar a formação profissional (Costa, Silva, Lima \& Ribeiro, 2018; Ribeiro, Ribeiro \& Soares, 2015).

Ainda nessa perspectiva, o Ministério da Educação preconiza que as diretrizes curriculares se apresentam como orientações acerca dos seus objetivos, fundamentos, requisitos em sua oferta, estratégias para a realização de seu planejamento, implementação e forma de avaliação. Seu objetivo principal destina-se à formação de profissionais voltadas para sua atuação, ensino e pesquisa, asseguradas pelos compromissos e princípios presentes na resolução $N^{\circ} 5$, de 15 de março de 2011, que toma como bases os princípios do SUS (Brasil, 2011).

Em relação às Diretrizes Curriculares Nacionais para os cursos de graduação em Psicologia (DCNP) de 2011, o Ministério da Educação explicita as principais orientações acerca da formação profissional do psicólogo, por meio de princípios que visam a ética nas relações em que este constrói com seus clientes ou os demais profissionais de psicologia, a saber: pluralidade na compreensão dos fenômenos psicológicos e sua relação com os fenômenos sociobiológicos; o desenvolvimento do conhecimento acerca dos fenômenos psicológicos; capacitação contínua; criticidade na atuação em contextos variados, entre outros, sendo configuradas em todo o país como orientações gerais para as instituições de ensino superior (Brasil, 2011). Em seu Art. $4^{\circ}$, a resolução aponta quais habilidades e competências a formação em psicologia deve proporcionar ao estudante para o seu exercício profissional:

I. Atenção à saúde: os profissionais devem estar aptos a desenvolver ações de prevenção, promoção, proteção e reabilitação da saúde psicológica e psicossocial, tanto em nível individual quanto coletivo, bem como a realizar seus serviços dentro dos mais altos padrões de qualidade e dos princípios da ética/bioética;

II. Tomada de decisões: o trabalho dos profissionais deve estar fundamentado na capacidade de avaliar, sistematizar e decidir as condutas mais adequadas, baseadas em evidências científicas;

III. Comunicação: os profissionais devem ser acessíveis e devem manter os princípios éticos no uso das informações a eles confiadas, na interação com outros profissionais de saúde e o público em geral;

IV. Liderança: no trabalho em equipe multiprofissional, os profissionais deverão estar aptos a assumirem posições de liderança, sempre tendo em vista o bem-estar da comunidade;

V. Administração e gerenciamento: os profissionais devem estar aptos a tomar iniciativas, fazer o gerenciamento e a administração da força de trabalho, dos recursos físicos e materiais e de informação, da mesma forma que devem estar aptos 
a serem empreendedores, gestores, empregadores ou líderes nas equipes de trabalho;

VI. Educação permanente: os profissionais devem ser capazes de aprender continuamente, tanto na sua formação, quanto na sua prática, e de ter responsabilidade e compromisso com a sua educação e o treinamento das futuras gerações de profissionais, estimulando e desenvolvendo a mobilidade acadêmica e profissional, a formação e a cooperação através de redes nacionais e internacionais (Brasil, 2011, p. 2).

Centra-se na produção de competências no processo educativo modifica as metodologias utilizadas em sala, mas não significa que sejam suficientes para promover uma educação libertadora e uma mudança nas relações sociais. Destaca-se que é a partir da década de 1970, que o conceito de competência vai ganhando espaço na produção de conhecimento nos espaços educativos ligado a uma lógica tecnicista.

Perrenoud (2013) é um dos autores que defende essa proposta educativa, apresenta que as competências estão ligadas a uma condição de mobilização de atitudes eficazes diante de uma situação as quais são apoiadas em conhecimentos, mas não limitadas a eles. Percebe-se, portanto que o conceito está ligado a capacidade de realizar uma ação (tarefa) diante de um fato. Ele destaca que a competência não pode ser observada, mas ocorre por meio de um processo contínuo. É a capacidade de dar condições para que se consiga chegar a algo esperado, sendo ainda algo aleatório e não previsível, no qual seu processo se torna possível devido ao diálogo por relações interpessoais e intrapessoais, promovendo ao indivíduo uma responsabilização e inserção social.

O autor aponta que dentro dos sistemas educacionais o termo competência acaba adquirindo múltiplas concepções. Devido a isso, torna-se comum surgir divergências conflitantes na semântica de sua concepção, devido à falta de identificações e manuseio, interferindo ainda desde a concepção e planejamento dos objetivos de um curso até nos conteúdos transmitidos em sala de aula. (Perrenoud, 2013).

Lima e Souza (2014) apontam que as DCNP apresentam dois pontos para formação profissional. De um lado, almeja a formação de profissionais crítico e político com as questões sociais e de outro, um sujeito aprisionado com a concepção ideológica de mercado, negando assim a primeira vertente. Contudo, ao se colocar dentro de modelos formais de educação ao elaborar modelos formadores como nas DCNP corroboram apenas com uma lógica adaptativa e conservadora, não tendo assim relação com a leitura crítica de homem e mundo. A concepção de competências como capacidade de agir pode atrelar a formação ao conceito tecnicista de resposta adaptativa ao mercado.

Já Pereira e Lages (2013) apontam que o processo de adaptabilidade do estudante, pautado na filosofia pragmática, que tem base no tripé competência qualificação - adaptabilidade alimenta a perspectiva individualista e o status quo de atendimento a exigências do mercado e é incapaz de promover um comprometimento ético-político com o SUS enquanto garantia de direitos. Ramos (2001) corrobora com essa reflexão ao considerar que as competências se atrelam a produção e tendem a uma profissionalização de tipo liberal, com base na adaptabilidade individual às mudanças socioeconômicas.

Por sua ênfase no individualismo, a pedagogia das competências pode contribuir para o senso comum de competitividade e valorização dos bens privados, como a espoliação do público por grupos e corporações. Os efeitos práticos de sua utilização para a formação em saúde podem comprometer o processo de universalização do acesso à saúde e a responsabilização do Estado brasileiro na estruturação do SUS. (Pereira e Lages, 2013, p. 333)

Essa reflexão aponta para uma incapacidade de a formação por competências atender a lógica da construção do público enquanto construção coletiva e de garantias de direitos, de acordo com o preconizado nas legislações do SUS resultante das lutas coletivas da reforma sanitária brasileira. Contudo, o ensino em saúde no Brasil permanece pautado nas orientações das Diretrizes curriculares nacionais com base no ensino por competências.

Em consonância com as Diretrizes Curriculares para cursos de Psicologia, a criação do Centro de Referência Técnica em Psicologia e Políticas Públicas (CREPOP) objetiva oferecer subsídios à atuação de profissionais da Psicologia no âmbito das políticas públicas; este é compreendido como uma iniciativa dos conselhos regionais/estaduais e federal do ano de 2006. Além de informações técnicas, este ainda exerce um papel político, já que se debruça sobre as 
questões sociais e éticas, por meio de orientações do fazer profissional (CREPOP, 2019).

O órgão, então, surge por meio de questionamentos provenientes na década de 1970, que só foram incorporados nas duas décadas seguintes devido à inserção e atuação do psicólogo no campo social, fazendo-se assim necessário uma maior compreensão sobre sua atuação dentro desses campos. Com isso, diversas iniciativas do Conselho Federal de Psicologia surgiram, bem como da relação existente entre o Estado e a atuação desses profissionais, fazendo com que as ideias para sua criação ocorressem durante $o$ $\checkmark$ Congresso Nacional de Psicologia, sendo seu projeto apresentado pelo Banco Social de Serviços em 2005 (CREPOP, 2019).

Assim, partindo do pressuposto de que o profissional de psicologia pode atuar em diversas políticas de saúde, se faz necessário compreender a existência de possíveis consonâncias entre as Diretrizes Curriculares para a formação de psicólogos com aquilo que é exposto pelo CREPOP, já que este último diz da prática profissional. Mesmo devendo haver uma relação nítida de orientações entre documentos que direcionam a formação acadêmica e aqueles que guiam a prática do profissional, não existe um estudo que faça a análise discursiva para avaliar se há uma interrelação entre as orientações presentes nesses dois documentos.

Diante disso, este trabalho tem por objetivo relacionar os discursos presentes nas referências técnicas paras o trabalho do psicólogo elaborada pelo CREPOP com os discursos das competências técnicas preconizadas pelas Diretrizes Curriculares Nacionais para os cursos de graduação em Psicologia (DCNP). Para isso, busca-se problematizar as competências técnicas para a formação de psicólogos; identificar as principais competências técnicas profissionais elaboradas pelo CREPOP para se trabalhar no SUS; e correlacionar quais competências preconizadas pelo CREPOP se relacionam com as DCNP.

\section{Metodologia}

Essa pesquisa configura-se como um estudo documental, que descreve os discursos presentes nas Referências Técnicas para o trabalho de psicólogos elaboradas pelo CREPOP e sua relação com as competências técnicas preconizadas pelas Diretrizes Curriculares Nacionais para os cursos de graduação em Psicologia. Trata-se de uma pesquisa construcionista, por adotar uma postura antiessencialista, antirrealista e não representacionista frente às questões apresentadas pelo mundo. Assim, aqui não se pretende ter ou construir verdades absolutas, inquestionáveis e impostas. Essa postura é compreendida como antiessencialista, já que parte do pressuposto de indivíduos que se constituem em uma perspectiva marcada por questões sociais e históricas. E antirrealista, devido a não compreender uma única realidade, mas a existência de diversas perspectivas sobre uma vivência. Por fim, não representacionista, já que a linguagem adquire um caráter de ação na sociedade em que esta se encontra, onde a prática discursiva seria, assim, o(s) discurso(s) produzidos nesse contexto (Méllo, Silva, Lima \& Di Paolo, 2007; Medrado, Spink \& Méllo, 2014; Macêdo, 2018).

Para isso, foram utilizados os documentos das Referências Técnicas do CREPOP, de janeiro de 2007 a setembro de 2019; e as Diretrizes Curriculares Nacionais para os cursos de graduação em Psicologia, do ano de 2011; sendo estes documentos, de acordo com a classificação de Marconi e Lakatos (2003), compreendidos como arquivos de domínio público, de ordem primária e contemporâneos.

Em um primeiro momento, foi realizado um levantamento de todas as Referências Técnicas do CREPOP no período já citado, totalizando 18 documentos. Após a realização de uma leitura flutuante do material encontrado, foram excluídos documentos considerados desatualizados por terem sido republicados com a mesma temática; assim, optou-se por analisar as referências mais recentes. Após isso, optou-se por trabalhar com as referências que tinham como propósito o direcionamento do psicólogo na atuação de políticas públicas de saúde, e que trabalhassem com demandas que possuem relação direta ou indireta com o processo de saúde mental dentro do SUS, resultando assim em quatro documentos. A partir do acesso a tais documentos foram selecionados apenas os capítulos que se referiam à atuação profissional.

Após a seleção do material, os documentos foram lidos na íntegra com o intuito de realizar a análise de discurso. Esse termo tende a ser atribuído a Michel Pêcheux, o qual partindo de uma perspectiva estruturalista realizava a análise automática do discurso considerando que as condições de produção de 
discursos são definidas "pelos lugares ocupados pelo emissor e receptor na estrutura de uma formação social" (SPINK, 2013, p. 20). Essa proposta de análise está mais próxima do que das atuais configurações da psicologia social discursiva.

A perspectiva de análise do discurso que foi utilizada nesse estudo, parte de uma perspectiva pós estruturalista e construcionista, tendo como autores de base Rorty (1979/1994), Gergen (1985) e Ibáñez (1993). O método aqui empregado segue o caminho das práticas discursivas e produção de sentidos e encontra ancoragem a partir de três dimensões básicas: linguagem, história e pessoa. (SPINK, 2013)

Para uma melhor visualização dos materiais utilizados na pesquisa, as informações das Referências Técnicas usadas foram apresentadas por meio de um quadro temático, buscando enfocar as seguintes dimensões: Título da Referência, Ano de publicação, Título do capítulo utilizado, e Resumo dos principais temas abordados no capítulo, conforme tabela de número 01 , sendo este considerado um mapa temático.

Tabela 1. Mapa de documentos analisados e temáticas principais

\begin{tabular}{|c|c|c|c|c|}
\hline $\begin{array}{l}\text { Referência de } \\
\text { identificação do } \\
\text { documento nas } \\
\text { análises dos } \\
\text { resultados }\end{array}$ & Título da Referência & $\begin{array}{c}\text { Ano de } \\
\text { Publicação }\end{array}$ & $\begin{array}{l}\text { Título do } \\
\text { Capítulo } \\
\text { Utilizado }\end{array}$ & $\begin{array}{l}\text { Temática principal do } \\
\text { documento }\end{array}$ \\
\hline Doc.1 & $\begin{array}{c}\text { Saúde do Trabalhador no } \\
\text { Âmbito da Saúde Pública: } \\
\text { Referências para a atuação } \\
\text { da(o) psicóloga(o) }\end{array}$ & 2019 & $\begin{array}{l}\text { Atuação da(o) } \\
\text { Psicóloga(o) em } \\
\text { Saúde do } \\
\text { Trabalhador }\end{array}$ & $\begin{array}{l}\text { Dispõe sobre as } \\
\text { principais formas de } \\
\text { atuação do psicólogo } \\
\text { com as demandas } \\
\text { ligadas à saúde do } \\
\text { trabalhador }\end{array}$ \\
\hline Doc. 2 & $\begin{array}{l}\text { Referências Técnicas Para } \\
\text { Atuação de Psicólogas(os) } \\
\text { em Políticas Públicas de } \\
\text { Álcool e Outras Drogas }\end{array}$ & 2019 & $\begin{array}{c}\text { Eixo 2: a(o) } \\
\text { Psicóloga(o) na } \\
\text { Rede Psicossocial } \\
\text { e a Política de } \\
\text { Atenção Integral } \\
\text { às(aos) } \\
\text { Usuárias(os) de } \\
\text { Álcool e Outras } \\
\text { Drogas } \\
\end{array}$ & $\begin{array}{l}\text { Dispõe sobre as } \\
\text { principais políticas } \\
\text { relacionadas ao } \\
\text { enfretamento de Álcool } \\
\text { e Outras Drogas, bem } \\
\text { como os desafios da } \\
\text { prática do psicólogo }\end{array}$ \\
\hline Doc.3 & $\begin{array}{l}\text { Referências Técnicas para } \\
\text { Atuação de Psicólogas(os) } \\
\text { no CAPS - Centro de } \\
\text { Atenção Psicossocial }\end{array}$ & 2013 & $\begin{array}{c}\text { Eixo III: A } \\
\text { Atuação da (o) } \\
\text { Psicóloga (o) na } \\
\text { Política do CAPS }\end{array}$ & $\begin{array}{l}\text { Dispõe sobre os } \\
\text { principais desafios na } \\
\text { atuação dentro do } \\
\text { Centro de Atenção } \\
\text { Psicossocial }\end{array}$ \\
\hline Doc.4 & $\begin{array}{c}\text { Referências Técnicas para a } \\
\text { Prática do(a) Psicólogo(a) } \\
\text { nos Programas de DST e } \\
\text { Aids }\end{array}$ & 2008 & $\begin{array}{c}\text { Eixo } 3 \text { - Atuação } \\
\text { do(a) } \\
\text { Psicólogo(a) em } \\
\text { Programas de } \\
\text { Dst/Aids }\end{array}$ & $\begin{array}{l}\text { Dispõe sobre a atuação } \\
\text { do psicólogo em } \\
\text { programas de suporte } \\
\text { a pessoas com Dst/Aids }\end{array}$ \\
\hline
\end{tabular}

O Mapa Temático é definido como um instrumento que possui como propósito a melhoria da comunicação já que este, por meio de visualização, transmite informações categorizadas e organizadas de um determinado material (Archela \& Théry, 2008). Para esta pesquisa, foi utilizada a metodologia de análise do discurso já explicitada aqui, que é conhecida como práticas discursivas e produção de sentido para a construção do Mapa Temático.

Segundo Rocha e Deusdará (2005), a análise do discurso é definida como uma metodologia qualitativa, que visa compreender os conteúdos presentes dentro do processo de comunicação, já que se fundamenta por meio de um rigor técnico de modo a se delimitar e se debruçar em um determinado objetivo. Esta ainda tem como objetivo a compreensão daquilo que está para além do escrito, do que está posto ao longo do texto, contribuindo, 
assim, para um maior aprofundamento do material e temática trabalhada, sendo esta constituída por meio das práticas discursivas.

Spink e Medrado (2013) definem práticas discursivas como uma linguagem em ação. Compreendida como a forma com que as pessoas se posicionam em meio às suas relações cotidianas, em seu dia a dia, a maneira como as pessoas produzem sentido, cujo elemento constitutivo é a dinâmica, ou seja, as vozes que são anunciadas e que se fazem presentes no cotidiano; e o conteúdo. Seu conceito ainda remete a um uso ativo da linguagem, propiciando, assim, momentos de rupturas, ressignificações e, consequentemente, produção de sentidos.

Ao adotar essa terminologia, o termo "discurso" pode ser destinado ao uso dos sistemas que compõem os sinais linguísticos e sua forma institucionalizada. Assim, acaba sendo possível fazer uma distinção das práticas discursivas, ou seja, a forma como as pessoas usam a linguagem em suas relações sociais para atribuir sentido; e a forma institucionalizada de seu uso, utilizado através da linguagem a partir da apropriação da forma de algum domínio do saber (Spink, 2010).

Santana, Rocha, Bernardes \& Ribeiro (2016) ainda apontam que o processo da linguagem em ação sugere que, mesmo de forma não intencional, passa a existir uma ampliação na forma de sua expressão, propiciando entre os interlocutores uma mudança em seus posicionamentos. Com isso, Spink e Medrado (2013) explicam que esse processo não fica restrito apenas às produções orais. Textos escritos, segundo os autores, acabam se constituindo por um ato impresso de fala, um elemento verbal de comunicação que é capaz de gerar ativas discussões em detrimento de seu conteúdo, como por exemplo: críticas, elogios, comentários de forma geral, orientações profissionais e entre outros. Assim, meios de comunicação como a televisão, a internet e o rádio, ao produzirem um enunciado, utilizam-se de estruturas pré-existentes dos sistemas da linguagem, exercendo uma função de posicionamento a ele e, necessariamente, os transformando em atos de fala.

Para o levantamento das competências nos documentos publicados pelo CREPOP, os textos foram lidos de forma exaustiva, onde as similitudes encontradas foram categorizas por cores distintas e, posteriormente, foram organizadas em mapas dialógicos, sendo definidas as competências como categorias. Primeiramente, foram elencadas as categorias presentes nas DCNP (Diretrizes Curriculares Nacionais para os cursos de graduação em Psicologia), em seguida foram elencadas novas categorias, sendo estas competências diferentes das postas nas DCNP, mas percebidas nos documentos em questão.

Nos mapas foram distribuídos os discursos do texto na ordem em que apareciam e dentro de colunas designadas a cada categoria. Foi feito um mapa dialógico para cada referência técnica, os quais não serão apresentados na íntegra na análise dos resultados, devido à ocupação de espaços. Contudo, haverá a disponibilização de uma consolidação desses mapas dialógicos em uma tabela com o título: Mapa dialógico de repertórios linguísticos das competências identificadas nos documentos do CREPOP e que servirá para guiar as análises discursivas.

No que diz respeito aos Mapas Dialógicos, Nascimento, Tavanti e Pereira (2014) apontam que sua construção se relaciona diretamente com a proposta teórico-metodológica de dar visibilidade ao processo de análise e de produção de práticas discursivas. Ao se debruçar sobre esta temática, o pesquisador busca compreender como o participante constrói sentidos no mundo que o rodeia, compreendendo seu repertório linguístico presente nas diversas formas de expressão em que a linguagem pode se apresentar.

Após o levantamento das competências destacadas pelo CREPOP, estas foram correlacionadas com as competências preconizadas para a formação de psicólogos, visando compreender as similitudes e diferenças presentes em ambos os materiais.

\section{Resultados e discussão}

Após leitura exaustiva das Referências Técnicas do CREPOP, foram selecionados para este estudo o total de quatro documentos, conforme apresentados com a Referência de identificação do documento nas análises dos resultados, Título da Referência, Temática principal do documento e Repertórios linguísticos abordados nos documentos (em acordo com categorias de competências das DCNP e Novas modalidades de categorias de competências identificadas nos documentos do (REPOP e não presentes nas DCNP). 
Tabela 2. Mapa dialógico de repertórios linguísticos das competências identificadas nos documentos do CREPOP (continua)

Repertórios linguísticos abordados nos documentos

Em acordo com categorias de competências das DCN's categorias de
Referência de identificação nas análises dos resultados do documento
Título da Temática

Referência principal do documento
Novas modalidades de competências identificadas nos documentos do CREPOP e não presentes nas DCN's

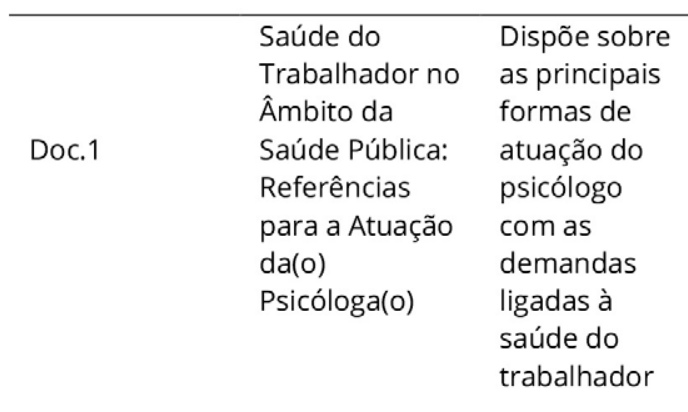

\section{Liderança:}

Papel decisivo, diferentes modalidades terapêuticas.

\section{Comunicação:}

Diálogo, entrevistas, oficinas, grupos, discussões.

\section{Administração e gerenciamento:}

Organização do trabalho, tempo, ritmo, sobrecarga de trabalho, gestão do trabalho,

\section{Educação permanente:}

Informações, bibliografia, seminários, estágios, capacitar técnicos.

\begin{tabular}{lll}
\hline & & Dispõe sobre \\
Rocerências & as principais \\
Técnicas Para & políticas \\
& Atuação de & relacionadas \\
& Psicólogas(os) & ao \\
em Políticas & enfretamento \\
& Públicas de & de Álcool e \\
Álcool e Outras & Outras \\
Drogas & Drogas, bem \\
& como os \\
& desafios da \\
& prática do \\
& psicólogo
\end{tabular}

Atenção à saúde:

Atenção integral, integralidade, cuidado, promoção de saúde, prevenção de saúde, bem-estar assistência integral.

Tomada de decisão:

Liderança:

Comunicação:

Dialógica, grupos, oficinas, assembleias, discutidas.

Administração e gerenciamento:
Trabalho com clínica ampliada:

Reconhecimento do subjetivo, valorização do conhecimento, singularidade, olhar para o contexto, sujeito.

Escuta terapêutica: Acolhimento, prática clínica, atividade clínica.

Trabalho colaborativo: Atuação interdisciplinar, busca coletiva, visão multiprofissional,

Ética dialógica:

Consentimento, espaços de reflexão, autoconhecimento, anonimato, fortalecimento dos trabalhadores,

\section{Trabalho com clínica} ampliada:

Rede, relações sociais, clínica ampliada, história de vida, cuidado compartilhado, metodologias de cuidado, determinantes sociais.

\section{Escuta terapêutica:}

Atendimento, escuta qualificada, acolhimento. participação voluntária. 
Tabela 2. Mapa dialógico de repertórios linguísticos das competências identificadas nos documentos do CREPOP (continuação)

Referência de identificação do documento nas análises dos resultados
Repertórios linguísticos abordados nos documentos

$\begin{array}{cc}\text { Título da } & \begin{array}{c}\text { Temática } \\ \text { principal do } \\ \text { documento }\end{array}\end{array}$

Em acordo com categorias de competências das DCN's
Novas modalidades de categorias de competências identificadas nos documentos do CREPOP e não presentes nas DCN's

Gestão em saúde, participação e controle, gestão dos serviços, articulação, parcerias.

Educação permanente:

Qualificados, educação permanente.

Cuidado colaborativo, cogestão, gestão participativa, multidisciplinar, multiprofissional, equipe, relações horizontais.

\section{Ética dialógica:}

Construções coletivas, subjetividade, ampliação da autonomia, liberdade, responsabilizações da vida, direitos humanos, compromisso éticopolítico.

Referências Dispõe sobre Atenção à saúde:
Técnicas para os principais Atuação de desafiosna Psicólogas(os) atuação no CAPS dentro do Centro de Centro de Atenção Atenção Psicossocial Psicossocial
Cuidado, intervenções, compromisso, tratamento, Projeto

Trabalho com clínica ampliada:

Trocas, encontro, conexões, vínculo, território, cotidiano, sujeito, singular, laços.

Tomada de decisão:

Decisão.

\section{Liderança:}

Comunicação:

Oficinas, assembleias.

Administração e gerenciamento: Arquitetura, espaços, recursos, lugares, tarefa, envolvidos, política, contornos.

Educação permanente:

Formação, acadêmica

\section{Escuta terapêutica:}

Clínica, acolhimento.

Trabalho colaborativo:

Equipe, rede, coletivo.

\section{Ética dialógica:}

Desconstróem, expressão, protagonismo, movimento, prática, querer, autonomia, cidadania, liberdade, desinstitucionalizar, ética, diferenças. 
Tabela 2. Mapa dialógico de repertórios linguísticos das competências identificadas nos documentos do CREPOP (conclusão)

Repertórios linguísticos abordados nos documentos

Em acordo com categorias de competências das DCN's categorias de competências

\begin{abstract}
Referência de identificação do documento nas análises dos resultados
\end{abstract}

Título da Referência
Temática principal do documento
Novas modalidades de identificadas nos documentos do CREPOP e não presentes nas DCN's

\begin{tabular}{|c|c|c|c|c|}
\hline Doc.4 & $\begin{array}{l}\text { Referências } \\
\text { Técnicas para a } \\
\text { Prática do(a) } \\
\text { Psicólogo(a) } \\
\text { nos Programas } \\
\text { de DST e Aids }\end{array}$ & $\begin{array}{l}\text { Dispõe sobre } \\
\text { a atuação do } \\
\text { psicólogo em } \\
\text { programas de } \\
\text { suporte a } \\
\text { pessoas com } \\
\text { Dst/Aids }\end{array}$ & $\begin{array}{l}\text { Atenção à saúde: Prevenção, } \\
\text { promoção, assistência, emocional, } \\
\text { mental, comunidade, } \\
\text { enfrentamento, preconceito, } \\
\text { discriminação, reabilitação. } \\
\text { Tomada de decisão: } \\
\text { Liderança: } \\
\text { Coordenar. Grupos. Familiares. } \\
\text { Comunicação: } \\
\text { Palestras, oficinas treinamentos, } \\
\text { ação educativa, coletiva, } \\
\text { acompanhar informações, } \\
\text { comunicação dos parceiros sexuais, } \\
\text { reflexões, cuidado } \\
\text { Administração e gerenciamento: } \\
\text { reinserção, mercado de trabalho, } \\
\text { equipes, } \\
\text { acompanhar, planejar, treinamento, } \\
\text { ações extramuros, noções de campo } \\
\text { e núcleo, vulnerabilidades, }\end{array}$ & $\begin{array}{l}\text { Trabalho com clínica } \\
\text { ampliada: } \\
\text { Sujeito, subjetiva, } \\
\text { singular, experiências } \\
\text { pessoais, redes, } \\
\text { humanização, vínculo. } \\
\text { Escuta terapêutica: } \\
\text { Acolhimento, } \\
\text { aconselhamento, escuta, } \\
\text { clínica, atendimento, } \\
\text { orientações. } \\
\text { Trabalho colaborativo: } \\
\text { Interdisciplinares, } \\
\text { multiprofissionais, } \\
\text { intersetorialidade, } \\
\text { gestão participativa, } \\
\text { regionalização. } \\
\text { Ética dialógica: } \\
\text { Empoderamento, } \\
\text { protagonistas, }\end{array}$ \\
\hline & & & $\begin{array}{l}\text { participação na gestão, mudança, } \\
\text { comportamento, reconhecimento, } \\
\text { tecnologias. } \\
\text { Educação permanente: } \\
\text { transformação, processos de } \\
\text { trabalho, aprendizagem contínua, } \\
\text { formação, estágio, estudos, } \\
\text { pesquisas, protocolos assistenciais, } \\
\text { questionários, humanização. }\end{array}$ & $\begin{array}{l}\text { participação, } \\
\text { compromisso, ético. }\end{array}$ \\
\hline
\end{tabular}

Após a análise do mapa dialógico de repertórios linguísticos, restaram as seguintes competências identificadas nos discursos das referências técnicas do CREPOP: Atenção à Saúde, Trabalho com Clínica Ampliada, Tomada de Decisão, Comunicação, Diálogo, Liderança, Administração e Gerenciamento, Trabalho Colaborativo, Educação Permanente e Ética Dialógica. Essa análise consolida uma discussão disposta nos tópicos seguintes: 
Tabela 3. Ordem de apresentação da análise discursiva das competências identificadas no discurso

\begin{tabular}{|c|c|}
\hline Categorias ampliadas de análise do discurso & Competências relacionadas \\
\hline $\begin{array}{l}\text { Atenção à saúde e seus desdobramentos para uma } \\
\text { clínica ampliada }\end{array}$ & $\begin{array}{l}\text { Atenção à Saúde } \\
\text { Trabalho com Clínica Ampliada }\end{array}$ \\
\hline $\begin{array}{l}\text { Políticas de saúde e seus modelos de tomada de } \\
\text { decisões }\end{array}$ & Tomada de decisão \\
\hline $\begin{array}{l}\text { Comunicação e diálogo: relações e implicações para as } \\
\text { políticas públicas }\end{array}$ & $\begin{array}{c}\text { Comunicação } \\
\text { Diálogo } \\
\text { Escuta Terapêutica }\end{array}$ \\
\hline $\begin{array}{c}\text { O processo de Liderança e gestão participativa nos } \\
\text { equipamentos de saúde }\end{array}$ & Liderança \\
\hline Administração, gerenciamento e gestão participativa & $\begin{array}{l}\text { Administração e Gerenciamento } \\
\text { Gestão Participativa }\end{array}$ \\
\hline $\begin{array}{l}\text { Educação permanente e suas implicações para a } \\
\text { construção de uma ética dialógica }\end{array}$ & $\begin{array}{c}\text { Educação Permanente } \\
\text { Ética dialógica }\end{array}$ \\
\hline
\end{tabular}

\section{Atenção à saúde e seus desdobramentos para uma clínica ampliada}

De acordo com Matta e Morosini (2008), a atenção à saúde caracteriza-se como uma organização estratégica que leva em consideração os fatores sociais, políticos e históricos de uma determinada população para a prestação de cuidados em saúde que esta necessita. Aqui, parte-se de uma prática que rompe o modelo médico hospitalocêntrico de práticas curativas, assistencialistas e individualistas, ao focalizar como centro do cuidado as reais necessidades do local a que este se destinar, na criação de estratégias, programas e serviços de saúde.

Observou-se que a competência de atenção à saúde é a que se apresenta com maior ênfase dentro das resoluções analisadas. As práticas de prestação de cuidado na atenção à saúde se direcionam a atividades amplas, que vão desde a promoção, prevenção e reabilitação de agravos à saúde, sendo estas práticas que possuem como premissas os princípios do SUS e dos direitos humanos, conforme explicita os recortes de discursos expostos abaixo:

...seguindo as diretrizes do SUS, as ações desenvolvidas devem ser orientadas para a promoção, a prevenção, a assistência e a reabilitação... (Doc. 01, p. 33)

... a leitura dos condicionantes sociais, das condições e da organização do trabalho na determinação do processo de adoecer e sofrer no trabalho...

(Doc. 01, p. 32)
... trabalham tendo como princípio básico a defesa dos direitos humanos e como diretriz a ampliação da autonomia e da participação social dos usuários.

(Doc. 02, p. 49)

A adesão ao tratamento ou sua ausência deve ser sempre problematizada... compromisso com a vida, o cuidado e os direitos. (Doc. 03, p. 102)

Pode-se inferir que a grande relação encontrada com a competência de atenção à saúde se deu em decorrência de tais práticas se apresentarem dentro das políticas públicas de saúde, e estas basearem seu funcionamento através de lei 8080/90 e, consequentemente, os princípios do SUS. Assim, o alinhamento da formação profissional por meio de diretrizes que vão ao encontro do modelo de saúde existente no país acaba possibilitando ao estudante uma melhor compreensão acerca da realidade com que este vai se deparar em sua futura atuação e, consequentemente, possibilita o desenvolvimento de competências que possam se adequar ao contexto social em que o estudante se encontra, adquirindo ainda uma maior criticidade em suas intervenções e atuação profissional e, consequentemente, estimulando o trabalho com clínica ampliada.

Uma clínica com tal nível de complexidade pede formação à altura. (Doc. 03, p. 102)

A análise também constatou que em todas as referências se apresentavam discursos que remetiam a uma atuação baseada em uma clínica do sujeito. Entretanto, aquelas mais atuais, "Saúde do 
Trabalhador no Âmbito da Saúde Pública: Referências para a atuação da(o) psicóloga(o)" e "Referências Técnicas Para Atuação de Psicólogas(os) em Políticas Públicas de Álcool e Outras Drogas" mostraram uma prática mais contextualizada, indo ao encontro do que é preconizado para o trabalho com clínica ampliada.

Compreendida como uma ferramenta que propicia ao sujeito um olhar com enfoques sociais, biológicos e psicológicos, a clínica ampliada busca identificar as singularidades de cada sujeito, já que parte do pressuposto de que o processo de saúde-doença é amplo, as decisões acerca dos diagnósticos e intervenções são discutidas e compartilhadas entre os profissionais, compreendem o indivíduo e sua inserção na sociedade, transversalidade na comunicação, na atuação profissional e apoio aos profissionais que prestam suporte à saúde (Brasil, 2009).

Campos (2003) ainda aponta que, ao se falar em clínica do sujeito, a doença acaba sendo compreendida como parte da vida, sem estigma ou redução à patologia. Assim, existiria uma ampliação do objeto de estudo e de suas intervenções, pois além de se pensar a doença, o sujeito e seu contexto de vida são considerados.

\section{Políticas de saúde e seus modelos de tomada de decisões}

Para Nassif (2019), a tomada de decisão possui um papel de direcionamento de determinadas atitudes por meio de crenças e experiências organizacionais vividas pelo agente da decisão. Este, por sua vez, acaba exercendo um papel centralizador e organizativo sobre as atividades da organização, exercendo uma dinamicidade por intermédio de valores e evidências presentes dentro de cada contexto organizacional. No que diz respeito à tomada de decisão, constatou-se que a competência, dentro das referências analisadas, não se apresentou de forma veemente como a competência de atenção à saúde, anteriormente analisada. Por meio do processo de análise do discurso, só foi observada uma referência técnica foco do presente estudo, sendo esta do ano de 2013, ligada à atuação do psicólogo frente a questões de trabalho e a outra no direcionamento de seu trabalho no CAPS.

Abertas as portas, suprimidas as grades _ primeira tomada de decisão, outra mudança deve se operar.

(Doc. 03, p. 96).
Os discursos apresentados pelos materiais analisados fazem menção a atitudes voltadas principalmente a decisões das melhores condutas aos usuários dentro do seu processo de cuidado nas políticas públicas, onde este tem um papel preponderante de incorporar as decisões da equipe, algo que aparentemente não estaria diretamente ligado à atuação de outro profissional por compreender um olhar mais profundo sobre a subjetividade.

... cada usuário desses serviços representa uma singularidade que, necessariamente, deve ser compreendida em todos os seus aspectos pela equipe de cuidado... a(o) psicóloga(o) pode e deve desempenhar um papel decisivo na incorporação como aspecto que pode ser patogênico na elaboração do PTS

(Doc. 01, p. 45-46).

... as(os) psicólogas(os) têm participado da elaboração de diferentes modalidades terapêuticas de atenção aos

trabalhadores... são adotadas variadas perspectivas teóricas... valorizam o conhecimento e a subjetividade dos trabalhadores... (Doc. 01, p. 38).

É válido inferir ainda que o pouco aparecimento da competência tomadas de decisões dentro das referências analisadas, pode ter relação com as tomadas de decisões nas políticas de saúde serem realizadas de forma compartilhada, assim ficando menos a cargo unilateral e um agente tomador de decisão e passando a ganhar uma dimensão de corresponsabilização.

Responsabilidade pelo cuidado com o usuário passa a ser compartilhada pela equipe e não mais de um único profissional (Doc. 03, p. 112).

... é preciso compatibilizá-la com as singularidades dos demais profissionais, de forma a integrar olhares, leituras e saberes, numa perspectiva interdisciplinar, interinstitucional e intersetorial... (Doc. 02, p. 74).

Assim, ao se pensar em estratégias para os usuários, muitas vezes, estas acabam sendo realizadas de forma multiprofissional e interdisciplinar. De forma individual, as tomadas de decisões acabam sendo direcionadas, assim como exposto na referência técnica "Saúde do Trabalhador no Âmbito da Saúde Pública: Referências para a atuação da(o) psicóloga(o)", para sua atuação específica na escolha de melhores formas de manejar o atendimento individual. 


\section{Comunicação e diálogo: relações e implicações para as políticas públicas}

Segundo Coriolano-Marinus, Queiroga, Ruiz-Moreno e Lima (2014), dentro dos equipamentos do SUS, a comunicação acaba sendo um instrumento de intermediação entre os profissionais de saúde e os usuários, já que esta configura-se como prática de troca de informações. A comunicação ainda é proveniente da relação humana, a qual pode ser expressa de forma verbal e/ou não verbal.

No decurso do processo de análise, a comunicação se apresentou dentro das referências em duas vertentes diferentes. Na primeira, a comunicação é colocada pelas referências, como algo técnico em seu processo de atuação, voltado para questões de transmissão de informações, principalmente ligadas a questões hierárquicas de saberes na relação profissional-comunidade, a qual proporciona relações verticais entre os sujeitos:

\section{Ações na comunidade - palestras, oficinas,} treinamentos (Doc. 4, p. 45).

Como atividades de educação em saúde pode-se destacar o desenvolvimento de cursos, seminários e estágios para técnicos, gestores e trabalhadores, com

a finalidade de capacitar técnicos integrantes das instâncias de controle social e trabalhadores em geral...

(Doc. 1, p. 41).

Para Cordeiro, Araújo, Costa \& Campos (2017), a comunicação pode ser compreendida como o processo de transmissão de informações por meio de mensagens. Dentre os diversos elementos tidos como básicos, podemos citar: a fonte, aquela que é responsável por emitir algo, que produz uma mensagem; o destinatário, aquele a quem se destina a mensagem transmitida; os codificadores, compreendido como os elementos que transformam a mensagem em sinais transmissíveis; o canal, visto como o meio de transporte para essa transmissão; e decodificador, que reconstrói as mensagens com base nos sinais que foram emitidos.

Os autores ainda apontam que a comunicação se diferencia de informação. Elucidam que, quanto mais emoções esta conseguir evocar e possuir elementos polissêmicos, maior será sua capacidade em comunicar algo, já que esta é capaz de mudar algo no destinatário, em função de sua capacidade de modificação e apaziguamento de incertezas dentro desse sistema (Cordeiro et al, 2017).
Observou-se que a comunicação ganhou uma segunda forma nas referências técnicas, sendo ampliada para a vivência do diálogo na relação entre profissionais e usuários e/ou entre profissionais e profissionais. De acordo com a Política Nacional de Educação Popular em Saúde, o diálogo pode ser compreendido como o encontro entre mundos distintos dos sujeitos, ou seja, é quando as pessoas colocam seus conhecimentos sociohistóricos à disposição de um outro na busca de uma transformação social e desenvolvimento de uma criticidade sobre aquilo que se debruçam (Brasil, 2013).

É válido salientar que as atividades do profissional de psicologia, sua atuação, independentemente do contexto em que se realizam, são permeadas por processos diálogos, já que devem favorecer relações assimétricas e de trocas de conhecimentos entre os sujeitos.

... o diálogo entre a vivência e a experiência cotidiana dos trabalhadores e o conhecimento técnico-científico...

(Doc. 1, p. 40).

Atuar junto à equipe no sentido de promover discussões, reflexões e ações sobre o cuidado/ humanização... (Doc. 4, p. 54).

Se levarmos ainda em consideração a relação existente por meio do diálogo apontado dentro das referências técnicas, é possível perceber que estas também direcionam a atuação do profissional de psicologia ao desenvolvimento da capacidade de ouvir, já que esta se destina a uma escuta terapêutica, competência que se mostra como especificidade de sua atuação.

Para Mesquita e Carvalho (2014), a escuta terapêutica pode ser definida como uma forma de estabelecimento de comunicação, em que o ouvinte busca compreender aquilo que se encontra dentro do processo de comunicação verbal e não verbal. A partir dos estudos de Carl Rogers, a escuta, dentro das escolas psicológicas, adquire uma concepção de se dispor a ouvir visando o crescimento e desenvolvimento do outro, propiciando um momento de fala e interesse de escuta, por meio de técnicas que propiciam a criação de vínculo e, consequentemente, um efeito terapêutico.

... a escuta, para expressão de vivências e reflexão do usuário sobre o sofrimento e suas causas...

(Doc. 2, p. 51). 
... oferecendo acolhimento, cuidado e suporte desde o momento mais grave, a crise... (Doc. 3, p. 93).

Conforme exposto nos discursos, a escuta terapêutica acaba sendo direcionada ao usuário por meio de diversas estratégias dentro dos equipamentos de saúde, sendo ainda compreendida como uma das especificidades de atuação do profissional de psicologia dentro das políticas de saúde. Tal competência acaba sendo direcionada prioritariamente para os usuários dos serviços, mas não o restringindo apenas a essa atividade, já que esta serve como um suporte para sua atuação dentro das demais atividades prescritas.

Percebe-se, assim, que o desenvolvimento da competência de comunicar pode até servir para resolução de problemas cotidianos e pontuais da prática do campo e do mercado de trabalho, contudo, é apenas o diálogo que pode transformar o fazer em prol de um compromisso social nitidamente implicado com as políticas públicas, pois este assume o sentido de reflexões sobre o cuidado, a humanização, as vivências e experiências.

\section{Administração? Gerenciamento? O processo de liderança e gestão participativa nos equipamen- tos de saúde}

Para Chanes (2006), liderança pode ser compreendida como uma forma da organização conseguir gerir suas atividades em prol de um objetivo comum. Necessariamente, esta baseia-se no princípio da confiança mútua, já que o desempenho da equipe depende da atuação de cada componente, podendo ainda ser expresso de diversas formas pelos líderes, que se torna um elemento fundamental para a obtenção de resultados pela equipe e/ou organização.

No que diz respeito à atuação de psicólogos em posições de liderança, observou-se que estas fazem menção somente ao exercício de sua prática em equipes multiprofissionais, assim como exposto na DCNP.

Na equipe mais ampla, os "oficineiros" também desenvolvem um trabalho junto com os demais membros da equipe... (Doc. 2, p. 55).

Pois, é somente por meio dessa visão multidimensional do problema que se torna possível apreender os mecanismos de individuação da doença...

(Doc. 1, p. 47).
Assim como exposto a partir dos discursos, a posição de liderança apontada pelas referências técnicas aponta uma prática exercida dentro de equipes multiprofissionais e interdisciplinares, sendo feita de forma compartilhada.

... a atuação transdisciplinar com equipes multiprofissionais... (Doc. 2, p. 64).

... a gestão participativa, as metas discutidas e definidas em espaços coletivos... (Doc. 2, p. 64).

Entretanto, ao se buscar discursos e/ou orientações que fazem menção à sua atuação como líderes dentro da equipe multiprofissional, observou-se uma escassez de orientações para os profissionais, tendo em vista uma maior prevalência de atividades voltadas para um processo de compartilhamento de liderança com os demais profissionais, em decorrência da necessidade e importância de sua atuação ocorrer com outros profissionais. Assim, sua atuação acaba se direcionando para um processo de gestão participativa.

Segundo Lorenzetti, Lanzoni, Assuiti, de Pires e Ramos (2014), o processo de gestão e administração dos equipamentos de saúde pode ser compreendido como um conjunto de práticas e saberes usados para a organização do serviço de saúde. Esta ainda leva em consideração os espaços em que o cuidado é prestado de forma direta, os mais variados equipamentos a partir do qual este cuidado vai ser prestado e a rede que se dispõe à prestação de cuidado. $O$ autor ainda aponta que, apesar das diversas transformações no modo de gerir provenientes da criação do SUS, dentro do Brasil, esta ainda se desenvolve baseada no modelo clássico de administração.

A teoria clássica da administração teve como principal representante Henri Fayol, cujo foco da teoria é a compreensão da gerência, em que as empresas, além de precisarem de atividades técnicas para a execução das atividades a que se predispõem, necessita desenvolver habilidades ligadas ao processo de administração, tendo em vista que todo indivíduo se insere ao longo da vida em diversas instituições e que estas necessitam ser administradas (Affonso \& Ferrari, 2018). 
Após a análise sobre a competência de administração e gerenciamento, observou-se que as diretrizes apontam para uma atuação voltada para o conhecimento do serviço, bem como um processo de gestão compartilhada.

Os discursos acabam sendo direcionados para processos de gerenciamento de atividades coletivas, em que o profissional de psicologia direciona sua atuação para uma gestão participativa ou compartilhada, já que dentro desse contexto, as decisões são tomadas pela equipe.

... a gestão participativa, as metas discutidas e definidas em espaços coletivos... (Doc. 2, p. 64).

... o empoderamento da comunidade mediante sua participação na gestão e a ênfase na mudança de comportamento (Doc. 4, p. 46).

De acordo com Chiavenato (2015), a gestão participativa aponta para uma estrutura organizacional em que cada colaborador acaba exercendo um papel preponderante dentro das decisões organizacionais; aqui todos possuem o direito de discordar, questionar e opinar, já que esta parte do princípio da democracia no processo de tomada de decisões. Esta ainda possui como aspectos fundamentais a vontade de participar, a motivação em poder contribuir com algo e o envolvimento cognitivo e comportamental daqueles que participam desse processo. Com isso, ainda se pressupõe mudanças dentro da cultura organizacional, tendo em vista que este modelo de gestão possibilita a horizontalidade nas relações dentro dos grupos.

Já o trabalho colaborativo é apontado por Damiani (2008), quando os trabalhadores de um determinado grupo, na realização de suas atividades, acabam apresentando um suporte com o intuito de atingir um determinado resultado almejado por todos. Nesse processo, o trabalho colaborativo não visa hierarquização, mas parte do pressuposto de uma responsabilização compartilhada.

Com isso, ao se analisar as referências técnicas, o trabalho colaborativo também se apresentou dentro dos discursos como algo presente dentro das diversas formas de atuação do profissional de psicologia.

... trabalho em equipe e em rede. Este conjunto formam os pontos de orientação que organizam e dão sentido ao cuidado nestes lugares (Doc. 3, p. 94).
Nota-se, assim, que o nexo entre saúde/doença mental exige olhar e atuação interdisciplinar, na qual a(o) psicóloga(o) tem papel de destaque. (Doc. 1, p. 45).

... ao se inserirem nas equipes interdisciplinares que realizam as ações de vigilância, as(os) psicólogas(os) podem colaborar para a apreensão de informações...

(Doc. 1, p. 41).

Assim, levando em consideração esses discursos, é válido ressaltar que a menção sobre o trabalho colaborativo vai ao encontro das competências técnicas da Associação Brasileira de Ensino e Pesquisa (ABEP): "Liderança" e "Administração e Gerenciamento". Em ambas, o psicólogo é estimulado a estar apto para ocupar um papel de centralidade dentro de equipes e/ou serviços, caso seja necessário. Nas referências, por sua vez, é observado que esse papel acaba dando lugar a uma gestão compartilhada, a um trabalho colaborativo, em que todos que compõem a equipe/ equipamento de saúde podem e devem auxiliar nas tomadas de decisões, possuindo assim responsabilidades com a equipe e com o usuário.

\section{Educação permanente e suas implicações para a construção de uma ética dialógica}

Compreendida como uma prática no exercício de ensinar e aprender, a educação permanente em saúde leva em consideração uma prática significativa para os atores envolvidos no processo, a educação permanente leva em consideração as práticas, crenças, valores e saberes existentes no cotidiano, partindo ainda do pressuposto de uma educação problematizadora, destinando-se a todos aqueles que compõem o SUS (Brasil, 2016).

Em relação à educação permanente, constatou-se que as referências técnicas trazem seu desenvolvimento por meio de questões desde a formação de novos profissionais de saúde até o contínuo aprendizado após a formação.

... o serviço de saúde deve ser compreendido como local de aprendizagem contínua, participativa e potencialmente transformadora dos processos de trabalho... (Doc. 4, p. 47).

Viabilizar campo para estágio, contribuindo com a formação de novos profissionais (Doc. 4, p. 54). 
No âmbito da educação permanente dos profissionais, incluída a atualização técnico-científica, a(o) psicóloga(o) pode atuar na formação e gestão do trabalho em saúde... (Doc. 1, p. 42).

Assim, é possível inferir que dentro dos discursos encontrados, estes acabam fazendo uma maior alusão àquilo que seria definido como aprendizagem contínua.

A educação permanente se diferenciaria da educação contínua, pois esta última possui um alvo uniprofissional, baseada por uma prática autônoma e cujo principal objetivo é a atualização científica e técnica. Contudo, qualquer tentativa de separação entre a educação continuada e a educação permanente acabaria gerando uma atuação prisional que não compreenderia o todo, que seria fragmentada. Assim, uma acaba exercendo influência sobre a outra no processo de educação dos trabalhadores em saúde (Brasil, 2016).

Já Batista e Gonçalves (2011) apontam ainda que a educação permanente tem como intuito preencher brechas ou até mesmo fomentar a graduação dos profissionais de saúde. Esta deve ser pensada de forma descentralizada, levando em consideração a realidade de cada espaço a que se destina, bem como utilizar-se de metodologias significativas na busca de novas formas de aprender e ensinar, garantindo assim a participação de todos aqueles que fazem parte desse processo: a gestão, a assistência e a universidade. Com isso, não apenas os trabalhadores seriam contemplados dentro dessas práticas, mas a própria comunidade de estudantes acabaria sendo alvo da educação permanente.

Além de se voltar para uma formação profissional a educação permanente acaba se direcionado também ao sujeito que é acompanhado pelo profissional de saúde e que reflete com este sobre os cuidados que Ihe são ofertados. Já o profissional, ao se debruçar em referenciais teóricos que permeiam sua prática profissional, acaba, consequentemente, se desenvolvendo enquanto sujeito autônomo, crítico e empoderado dentro dos espaços de atuação, conforme explicitado nos discursos abaixo:

... o que gera um pensamento crítico sobre a realidade, possibilita a transformação de relações de poder e aumenta a capacidade de os indivíduos sentirem-se ativos nos processos que determinam suas vidas

(Doc. 1, p. 39).
... construção de autonomias e a geração de usuários mais críticos e livres, donos e protagonistas de suas histórias (Doc. 2, p. 63).

... manejos criativos e singulares para fazer contorno à dor intensa e assegurar ao sujeito os direitos de um cidadão (Doc. 3, p. 94).

Conforme observado, os discursos ainda apresentam uma prática voltada ao empoderamento dos sujeitos, propiciando que estes se tornem ativos, participativos e autônomos dentro do processo de saúde-doença. Os discursos fazem, assim, referência àquilo que é definido por Spink (2000) como ética dialógica.

... sempre considerando as questões éticas envolvidas: anonimato, consentimento e participação voluntária

(Doc. 1, p. 41).

... potencializando as parcerias e as construções coletivas, buscando a integralidade em nossas intervenções (Doc. 2, p. 63).

... Formação acadêmica, mas, sobretudo, formação eticamente orientada para a liberdade, capaz, portanto, de refletir criticamente sobre o seu fazer...

(Doc. 3, p. 102).

A ética dialógica pode ser compreendida como uma competência que parte do princípio da interacionalidade, ou seja, leva em consideração para sua existência a participação de todos no processo. Considera também o contexto social a partir do qual se fala, além de compreender que, nessa troca dialógica o indivíduo se constitui enquanto ser social (Spink, 2000).

\section{Considerações finais}

Observou-se que a maior relação das Diretrizes Curriculares Nacionais para os cursos de Psicologia (DCNP) com as Referências Técnicas do CREPOP acontece para aquelas que estão relacionadas com a atenção à saúde no contexto das políticas públicas de saúde, como a promoção de saúde. Outras competências como liderança, tomada de decisão e administração e gerenciamento, são ampliadas por outras competências que englobam uma atuação do profissional de psicologia de forma compartilhada, principalmente ligada ao trabalho interdisciplinar e multiprofissional preconizado nos equipamentos. 
A comunicação é outra competência que, nas orientações técnicas, torna-se ampliada, pois deixa de ter a dimensão conceitual de transmissão de conhecimentos para se voltar para a construção de diálogo. Já a educação permanente surge como uma competência importante para sua atuação, sendo direcionada para a formação profissional e para a relação educativa com os usuários do SUS.

Observou-se ainda que atuar baseado apenas nas competências técnicas preconizadas nas DCNP acaba fornecendo uma prática muitas vezes limitada, que não consegue dar vazão a todas as formas de atuação do profissional de psicologia e, necessariamente, em sua atuação com os sujeitos. Assim, constatou-se ainda que tais competências se relacionam diretamente com outros conceitos, apresentados no presente estudo como novas competências, cujo intuito é ter uma maior ampliação nas atividades e intervenções realizadas pelo psicólogo.

Assim, como discursos que se relacionavam à forma de atuação e que não se apresentavam dentro das competências técnicas, pode-se observar: trabalho com clínica ampliada, diálogo, trabalho colaborativo e ética dialógica.

Por meio disso, para que se tenha profissionais aptos a atuarem dentro das políticas públicas de saúde, se faz necessário o alinhamento dentro das competências estabelecidas pelas DCN's com aquilo que é orientado para a atuação deste profissional pelo CREPOP, para que se consiga proporcionar a formação mais abrangente possível, preparando-os para as mais variadas demandas que este profissional pode encontrar durante o exercício de sua profissão, já que o compromisso não se liga apenas a ações concretas, mas volta-se para um compromisso político com o projeto ético-democrático popular, social. Nesse sentido, a perspectiva de competências como preparatórias para a inserção no mundo do trabalho que é apresentada nas DCN's não consegue fazer uma correspondência direta com o papel dos profissionais de psicologia no âmbito da sua atuação, pois esse Âmbito requer um compromisso crítico e social com a construção de um mundo equânime, premissas que ficam em segundo plano no universo de produção liberal capitalista.

\section{Contribuições dos autores}

Coêlho, I. C. participou da concepção, delineamento, busca e análise dos dados da pesquisa, interpretação dos resultados e redação do artigo científico. Macêdo, M. A. participou da concepção, delineamento, busca e análise dos dados da pesquisa, interpretação dos resultados e revisão do artigo científico.

\section{Conflitos de interesses}

Nenhum conflito financeiro, legal ou político envolvendo terceiros (governo, empresas e fundações privadas, etc.) foi declarado para nenhum aspecto do trabalho submetido (incluindo, mas não se limitando a subvenções e financiamentos, participação em conselho consultivo, desenho de estudo, preparação de manuscrito, análise estatística, etc.).

\section{Referências}

Affonso, L.M. F., \& Ferrari, F. L. (2018). Teorias da administração. Porto Alegre: SAGAH.

Archela, R. S., \& Théry, H. (2008). Orientação metodológica para construção e leitura de mapas temáticos. Confins, 3. Recuperado de http://www.uel.br/cce/geo/didatico/omar/ pesquisa_geografia_fisica/Construcao_LeituradeMapas.pdf

Batista, K. B. C., \& Gonçalves, O S. J. (2011). Formação dos Profissionais de Saúde para o SUS: significado e cuidado. Saúde e Sociedade, 20(4), 884-899. Recuperado de http:// www.scielo.br/pdf/sausoc/v20n4/07.pdf. doi: 10.1590/ $\underline{\text { S010412902011000400007 }}$

Brasil. Ministério da Saúde. (2009). Clínica Ampliada e Compartilhada. Brasília: Ministério da Saúde. Recuperado de http://bvsms.saude.gov.br/bvs/publica coes/clinica_ ampliada_compartilhada.pdf

Brasil. Secretaria de Estado da Saúde do Tocantins - SESAU. (2016). Cartilha Educação Permanente. Brasília: Secretaria de Estado da Saúde do Tocantins - SESAU. Recuperado de https://central3.to.gov.br/arquivo/291540/

Campos, G. W. S. (2003). Clínica do Sujeito: por uma clínica reformulada e ampliada. In G. W. S. Campos. Saúde Paideia. São Paulo: Hucitec,

Centro de Referências Técnicas em Psicologia e Políticas Públicas (2009). Referências Técnicas em Psicologia e Políticas Públicas [Internet]. Recuperado de http://crepop.pol.org.br/ conheca-o-crepop

Chanes, M. (2006). Os desafios na formação de gestores líderes em saúde. O mundo da saúde, 30(2), 326-331. Recuperado de http://www.saocamilo-sp.br/pdf/mundo_saude/35/ desafios_formacao.pdf 
Chiavenato, I. (2015). Construindo e reconstruindo o espírito de equipe no trabalho. In I. Chiavenato (Org). Gerenciando com as pessoas: transformando o executivo em um excelente gestor de pessoas (pp.71-90). São Paulo: Manole.

Conselho Federal de Psicologia. (2008). Referências Técnicas para a Prática do(a) Psicólogo(a) nos Programas de Dst e Aids. Brasília: Conselho Federal de Psicologia. Recuperado em http://crepop.pol.org.br/wp-content/uploads/2010/11/ DST_AIDS.pdf

Conselho Federal de Psicologia. (2013). Referências Técnicas para a Atuação de Psicólogas(os) no CAPS - Centro de Atenção Psicossocial. Brasília: Conselho Federal de Psicologia.. Recuperado de http://crepop.pol.org.br/wp-content/ uploads/2015/09/CREPOP_2013_CAPS.pdf

Conselho Federal de Psicologia. (2019). Referências Técnicas para Atuação de Psicólogas(os) em Políticas Públicas de Álcool e Outras Drogas. Brasília: Conselho Federal de Psicologia. Recuperado de https://site.cfp.org.br/publicacao/ referencias-tecnicas-para-atuacao-de-psicologasos-empoliticas-publicas-de-alcool-e-outras-drogas/

Conselho Federal de Psicologia. (2019). Saúde do Trabalhador no Âmbito da Saúde Pública: Referências Para a Atuação da(o) Psicóloga(o). Brasília: Conselho Federal de Psicologia. Recuperado de http://crepop.pol.org.br/wp-content/ uploads/2019/10/RT-Sa\%C3\%BAde-do-Trabalhador-NOVA. pdf

Cordeiro, R, Q. F., Araújo, A. C. S., Costa, M., \& Campos, C. R. P., Teorias da comunicação. (2017). In R, Q. F. Cordeiro, A. C. S. Araújo, M. Costa, \& C. R. P. Campos (Orgs.), Elementos básicos do processo de comunicação (pp. 45-52). Porto Alegre: SAGAH.

Coriolano-Marinus, M. W. L., Queiroga, B. A. M., Ruiz-Moreno, L., \& Lima, L. S. (2014). Comunicação nas práticas em saúde: revisão integrativa da literatura. Saúde e Sociedade, 23(4),1356-1369. Recuperado de https:// www.scielo.br/scielo.php?script=sci_arttext\&pid=S010412902014000401356\&lng=pt\&tlng=pt. doi: 10.1590/S010412902014000400019

Costa, D. A. S., Silva, R. F., Lima, V. V., \& Ribeiro, E. C. O. (2018). Diretrizes curriculares nacionais das profissões da Saúde 2001-2004: análise à luz das teorias de desenvolvimento curricular. Interface, 22(67),11831195. Recuperado de http://www.scielo.br/scielo. php?pid=S1414-32832018005013102 \&script=sci_ abstract\&tIng=pt. doi: 10.1590/1807-57622017.0376

Damiani, M. F. (2008). Entendendo o trabalho colaborativo em educação e revelando seus benefícios. Educar em Revista, (31), 213-230. Recuperado de https://www.scielo.br/ scielo.php?pid=S0104-40602008000100013\&script=sci_ abstract\&tlng=pt. doi: 10.1590/S0104-40602008000100013
Gergen, K. J. (1985). The social constructionist movement in modern Psychology. American Psychologist, 40(3), 266275. Recuperado de https://www.researchgate.net/ publication/302871718_The_Social_Constructivist_ Movement_in_Modern_Psychology. doi: 10.1037/0003$\underline{066 \times .40 .3 .266}$

Ibáñez, T. (1993). Construccionismo y Psicologia. Revista Interamericana de Psicologia, 28(1), 105-123. Recuperado de https://antroporecursos.files.wordpress.com/2009/03/ ibanez-t-2001-municiones-para-disidentes-15construccionismo-y-psicologia.pdf

Lima, V. C., \& Souza, R. T. (2014). Formação humana e competências: o debate nas diretrizes curriculares de Psicologia. Psicologia \& Sociedade, 26(3), 792-802. Recuperado de https://bit.ly/3jufdHL

Lorenzetti, J., Lanzoni, G. M. M., Assuiti, L. F. C., Pires, D. E. P., \& Ramos, F. R. S. (2014). Gestão em Saúde no Brasil: Diálogo com Gestores Públicos e Privados. Texto \& Contexto Enfermagem, 23(2),417-25. Recuperado de https://www.scielo.br/scielo.php?pid=S010407072014000200417\&script=sci_abstract\&tlng=pt. doi: 10.1590/0104-07072014000290013

Macêdo, M. A. (2018). Integração Ensino-Saúde-Comunidade: Educação Popular em Saúde e Coprodução de Competências na Graduação (Dissertação de Mestrado). Universidade Federal de Alagoas, Maceió, AL, Brasil. Recuperado de http://www.repositorio.ufal.br/handle/riufal/4789

Marconi. M. A., \& Lakatos, E. M. Técnicas de Pesquisa. (2003) In: M. A. Marconi, E. M. Lakatos (Orgs). Fundamentos da Metodologia Científica (pp.175-137). São Paulo: Editora Atlas S.A.

Matta, G. C., \& Morosini, M. V. G. (2008). Atenção à Saúde. In: I. B. Pereira, J. C. F. Lima (Orgs.). Dicionário da Educação Profissional em Saúde (pp.39-43). Rio de Janeiro: EPSJV.

Medrado, B., Spink, M. J. P., \& Méllo, R. P. (2014). Diários como atuantes em nossas pesquisas: narrativas ficcionais implicadas. In: M. J. P. Spink, J. Brigagão, V. Nascimento, \& M. Cordeiro (Orgs.). A produção de informação na pesquisa social: compartilhando ferramentas (pp.273-294). Rio de Janeiro, RJ: Centro Edelstein de Pesquisas Sociais.

Méllo, R. P., Silva, A. A., Lima, M. L. C., \& Di Paolo, A. F. (2007). Construcionismo, Práticas Discursivas e possibilidades de pesquisa. Psicologia \& Sociedade, 19(3), 26-32. Recuperado de https://www.scielo.br/scielo.php?pid=s0102$71822007000300005 \&$ script=sci_arttext. doi: $10.1590 /$ S0102-71822007000300005 
Mesquita, A. C., \& Carvalho, E. C. (2014). A Escuta Terapêutica como estratégia de intervenção em saúde: uma revisão integrativa. Revista da Escola de Enfermagem da USP, 48(6), 1127-36. Recuperado de http://www.scielo.br/ scielo.php?pid=S0080-62342014000601127\&script=sci_ arttext\&tIng=pt. doi: 10.1590/S0080-623420140000700022

Nascimento, V. L. V., Tavanti, R. M., \& Pereira C. C. Q. (2014). O uso de mapas dialógicos como recurso Analítico em pesquisas científicas. In M. J. P. Spink, J. Brigagão, V. Nascimento, \& M. P. Cordeiro (Orgs). A produção de informação na pesquisa social: compartilhando ferramentas (pp. 247-272). Rio de Janeiro, RJ: Centro Edelstein de Pesquisas Sociais.

Nassif, M. E. (2019). Crença e tomada de decisão: perspectiva de análise do comportamento gerencial para o estudo de uso de informação. Ciência da Informação, 48(2),1724. Recuperado de http://revista.ibict.br/ciinf/article/ view/4697/4164

Pereira, I. D. F., \& Lages, I. (2013). Diretrizes curriculares para a formação de profissionais de saúde: competências ou práxis? Trabalho Educação e Saúde, 11(2),319-338. Recuperado de https://www.scielo.br/scielo.php?scrip $\mathrm{t}=$ sci_abstract\&pid=S1981-77462013000200004\&Ing=pt\&n rm=iso. doi: $10.1590 / 51981-77462013000200004$

Perrenoud P. (2013). Competências e situações. In P. Perrenoud. Desenvolver COMPETÊNCIAS ou Ensinar SABERES? A escola que prepara para a vida (p. 44-85). Porto Alegre: Penso.

Pitombeira, D. F., Xavier, A. S., Barroso, R. E. C., \& Oliveira, P. R. S. (2016). Psicologia e a Formação para a Saúde: Experiências Formativas e Transformações Curriculares em Debate. Psicologia: Ciência e Profissão, 36(2), 280-291. Recuperado de http://www.scielo.br/scielo.php?pid=S1414-98932016 000200280\&script=sci_abstract\&tlng=pt. doi: 10.1590/1982-3703001722014. doi: 10.1590/19823703001722014

Portaria N ${ }^{\circ} 2.76$, de 19 de novembro de 2013. Institui a Política Nacional de Educação Popular em Saúde no âmbito do Sistema Único de Saúde (PNEPS-SUS). Recuperado de http://bvsms.saude.gov.br/bvs/saudelegis/gm/2013/ prt2761_19_11_2013.html

Ramos, M. N. (2001). A pedagogia das competências: autonomia ou adaptação?. São Paulo: Cortez.

Resolução $N^{\circ}$ 5, de 15 de março de 2011. Institui as Diretrizes Curriculares Nacionais para os cursos de graduação em Psicologia, estabelecendo normas para o projeto pedagógico complementar para a Formação de Professores de Psicologia. Recuperado de http://portal.mec.gov.br/index.php?option=com docman\&view=download \&alias=7692-rces005-11 pdf\&ltemid=30192
Rocha, D., \& Deusdará, B. (2005). Análise de Conteúdo e Análise do Discurso: aproximações e afastamentos na (re) construção de uma trajetória. Alea: Estudos Neolatinos, 7(2),305-322. Recuperado de https://www.scielo.br/scielo. php?script=sci_arttext\&pid=S1517-106X2005000200010. doi: $10.1590 / S 1517-106 \times 2005000200010$

Rorty, R. (1994). A filosofia e o espelho da natureza. Rio de Janeiro: Relume-Dumará.

Santana, A. L., Rocha, M. A., Bernardes, J. S., \& Ribeiro M. A. T. (2016). Estágio Curricular em Saúde e em Psicologia: Análise de Documentos de Domínio Público. Athenea Digital, 16(3),507-528. Recuperado de https:// atheneadigital.net/article/view/v16-n3-santana-rochabernardes-ribeiro. doi: $10.5565 / \mathrm{rev} / \mathrm{athenea.2036}$

Soares, V. A. R., Ribeiro, L. C. C., \& Ribeiro, M. (2015). Avaliação acadêmica acerca das Diretrizes Curriculares Nacionais em saúde. Revista Tempus Actas em Saúde Coletiva, 9(1),167187. Recuperado de http://www.tempusactas.unb.br/ind ex.php/tem pus/article/view/1700. doi: 10.18569/tempus. v9i1.1700

Souto, T. S., Batista, S. H., \& Batista, N. A. (2014). A Educação Interprofissional na Formação em Psicologia: Olhares de Estudantes. Psicologia: Ciência e Profissão, 34(1),32-45. Recuperado de https://www.scielo.br/pdf/pcp/v34n1/ v34n1a04.pdf. doi: 10.1590/S1414-98932014000100004

Spink, M. J. P. (2010). Linguagem e produção de sentidos no cotidiano (1a ed). Rio de Janeiro: Centro Edelstein.

Spink, M. J. P., \& Frezza, R. M. (2013). Práticas discursivas e produção de sentido: A perspectiva da psicologia social. In M. J. Spink (Org). Práticas Discursivas e Produção de Sentidos no Cotidiano (pp. 1-22). Rio de Janeiro, RJ: Centro Edelstein de Pesquisas Sociais.

Spink, M. J. P., \& Medrado, B. (2013). Produção de Sentido no Cotidiano: Uma abordagem teórico-metodológica para análise das práticas discursivas. In M. J. Spink (Org). Práticas Discursivas e Produção de Sentidos no Cotidiano. (pp. 22-41). Rio de Janeiro, RJ: Centro Edelstein de Pesquisas Sociais.

Spink. M. G. P. (2000). A ética na pesquisa social: da perspectiva prescritiva à interanimação dialógica. Psico, 31(1), 7-22. Recuperado de https://bit.ly/2CRuQbB 